\title{
In-vitro evaluation of dexpanthenol-loaded nanofiber mats for wound healing
}

\author{
Sakine Tuncay Tanrıverdi ${ }^{1 *}$, Bilge Suat ${ }^{1}$, Erkan Azizoğlu ${ }^{1}$, Fadime Aydın Köse ${ }^{2}$, \\ Özgen Özer ${ }^{1}$ \\ ${ }^{1}$ Ege University, Faculty of Pharmacy, Department of Pharmaceutical Technology, ${ }^{2}$ Ege University, Faculty of Pharmacy, \\ Department of Biochemistry, 35100, Izmir, Turkey
}

*For correspondence: Email: sakinetuncay@windowslive.com; Tel: +90 2323111368 ; Fax: +90 2323885258

\begin{abstract}
Purpose: To prepare a novel dexpanthenol (DEX)-loaded nanofiber mats for wound healing. Methods: A novel bioactive wound dressing formulation with dexpanthenol was developed by electrospinning method. Poly (lactic-co-glycolic acid), poly (ethylene oxide) and poly (caprolactone) were used as polymers. Morphological features, swelling properties, in-vitro release behavior, and cell viability properties of the formulations were evaluated.

Results: Morphological examination of mats confirmed successful formation of the fibers. Swelling of nanofiber mats results was $34.44 \pm 1.05,18.59 \pm 2.11,86.06 \pm 3.25$ and $44.62 \pm 1.75 \%$ for polycaprolactone (PCL), PCL +DEX, poly lactic-co-glycolic acid (PLGA) and PLGA + DEX, respectively, and occurred in a controlled manner. PLGA + DEX formulation has advantage over PCL + DEX and poly (ethylene oxide) (PEO) $+D E X$ due to controlled in-vitro release of $D E X$. The highest cell viability was afforded by PLGA+DEX formulation.

Conclusion: DEX-loaded PLGA nanofiber formulation may be useful as an alternative wound dressing due its suitable mechanical and biological properties.
\end{abstract}

Keywords: Dexpanthenol, Electrospinning, Wound dressing, Polycaprolactone, Poly lactic-co-glycolic acid, Poly (ethylene oxide)

\begin{abstract}
This is an Open Access article that uses a funding model which does not charge readers or their institutions for access and distributed under the terms of the Creative Commons Attribution License (http://creativecommons.org/licenses/by/4.0) and the Budapest Open Access Initiative (http://www.budapestopenaccessinitiative.org/read), which permit unrestricted use, distribution, and reproduction in any medium, provided the original work is properly credited.

Tropical Journal of Pharmaceutical Research is indexed by Science Citation Index (SciSearch), Scopus, International Pharmaceutical Abstract, Chemical Abstracts, Embase, Index Copernicus, EBSCO, African Index Medicus, JournalSeek, Journal Citation Reports/Science Edition, Directory of Open Access Journals (DOAJ), African Journal Online, Bioline International, Open-J-Gate and Pharmacy Abstracts
\end{abstract}

\section{INTRODUCTION}

Electrospining has been taken into consideration for many years by scientist; however its application to pharmaceutical field has been delayed. There has been increasing interest in polymeric nanofiber mats for biomedical applications [1]. One of the areas that this kind of products can be used is wound care especially in the form of wound dressings. Wound healing is known as a natural body response when the skin is damaged [2]. It is achieved through four programmed phases which are hemostasis, inflammation, proliferation, and remodeling. To be success in healing all four phases must occur at the right time and in the right. Healing process could be improved by application of pharmaceutics. Nanofibers can accelerate the wound healing process due to their large specific surface area. The nanofiber mat covers the 
wounded area, protects the damaged skin and stimulates wound healing process by active pharmaceutical agents [3].

There are several techniques used for the production of polymeric nanofibers [4]. Electrospinning technology overcomes the restrictions of conventional spinning. The electrospinning technic has a high rate of nanofiber production, simple set up and low production cost [5]. Polyvinyl alcohol (PVA), PCL, PEO, PLGA, gelatin, collagen, chitosan, Polyglycolic acid (PGA), fibrinogen and silk can be used for producing nanofiber mats. PLGA is a random biodegradable polymer and have been used for several drug-delivery preparations, surgical implants and tissue engineering scaffolds [6]. PEO is water soluble and has a linear structure [7]. It has been widely used for medical applications as electrospun nanofibers [8]. PCL is a semi-crystalline polymer which has non-immunogenecity, shows slow biodegradability and high biocompatibility [9] .

DEX is the stable alcoholic analog of pantothenic acid (vitamin B5). It is readily oxidized to pantothenic acid, a building block of of coenzyme A (CoA) [10]. It has been reported by clinical observations that topically applied DEX is an aid in superficial wound healing with minimal risk of skin irritancy [11].

The aim of this work to prepare and characterize DEX-loaded PLGA, PEO and PCL nanofiber mats by electrospinning method for wound healing. The formulations were characterized by microscopic observations, thickness measurement, FT-IR analyses, mechanical properties, swelling ability and loading capacity. In-vitro release behavior was and cell viabilities were also tested with sterilized formulations.

\section{EXPERIMENTAL}

Materials used include DEX produced by BASF which was a gift from ASSOS Pharmaceuticals (Turkey). PLGA, Hexafluoroisopropanol (HFIP) was purchased from Sigma (USA), Dimethylformamide (DMF) from Dasit, and Tetrahydrofuran (THF) from Merck. PEO and PCL were obtained from Sigma-Aldrich (USA). The other substances obtained commercially were analytical grades or higher.

\section{Preparation of nanofiber mats}

The polymer or polymer mixtures and DEX were dissolved in solvent or solvent mixtures to fabricate electrospun nonwoven nanofiber mats. Final volume of mixture was set to $100 \mathrm{ml}$. The solvents or solvents mixture were chosen in accordance to solubility of polymers. THF/DMF, HFIP and DMF were chosen for PLGA due to its solubility. Since PEO can be dissolved in water, distilled water is chosen as solvent. For the formulations F6, F7 and F8 chitosan was mixed with PEO and in this case different solvents were used. The best results were obtained with DCM/DMF mixture for PCL. The polymer solution with and without drug was loaded to a $5 \mathrm{~mL}$ plastic syringe which was fitted with a metallic needle. The flow rate was set on the syringe pump that was mounted horizontally, and the pump forced the piston of the syringe carrying the solution to move (12). The compositions of formulations were given in Table 1 and the conditions of electrospinning operation were summarized in Table 2.

Table 2: The parameters of electrospinning procedure

\begin{tabular}{lccc}
\hline $\begin{array}{l}\text { Formulation } \\
\text { code }\end{array}$ & $\begin{array}{c}\text { Solution } \\
\text { feed rate } \\
\text { (mL/h) }\end{array}$ & $\begin{array}{c}\text { Spinneret-to- } \\
\text { collector } \\
\text { distance }(\mathbf{c m})\end{array}$ & $\begin{array}{c}\text { Operating } \\
\text { Voltage } \\
\text { (kV) }\end{array}$ \\
\hline F1 & 2 & 15 & 13 \\
F2 & 2 & 15 & 10 \\
F3 & 4 & 15 & 16.4 \\
F4 & 2 & 15 & 10 \\
F5 & 1 & 20 & 15.5 \\
F6 & 0.5 & 15 & 17.5 \\
F7 & 2 & 26 & 24 \\
F8 & 0.3 & 26 & 13 \\
F9 & 1 & 20 & 15.5 \\
F10 & 2 & 15 & 17.5 \\
F11 & 2 & 15 & 18 \\
\hline
\end{tabular}

Table 1: Composition of prepared formulations

\begin{tabular}{|c|c|c|c|c|c|c|}
\hline Code & PLGA (\%) & PEO (\%) & PCL (\%) & $\mathrm{DEX}(\mathrm{mg} / \mathrm{mL})$ & Chitosan (\%) & Solvent \\
\hline F1 & 15 & & & & & THF/DMF (1:1) \\
\hline F2 & 15 & & & & & HFIP \\
\hline F3 & 15 & & & & & DMF \\
\hline F4 & 15 & & & 100 & & HFIP \\
\hline F5 & & 6 & & & & Distilled water \\
\hline F6 & & 1 & & & 1 & Acetic acid solution $(0.05 \%)$ \\
\hline F7 & & 1 & & & 1 & Acetone/ DCM (1:1) \\
\hline F8 & & 1.4 & & & 0.6 & Acetone/ DCM (1:1) \\
\hline F9 & & 6 & & 100 & & Distilled water \\
\hline F10 & & & 12 & & & DCM/DMF (1:1) \\
\hline F11 & & & 12 & 100 & & $\mathrm{DCM} / \mathrm{DMF}(1: 1)$ \\
\hline
\end{tabular}




\section{Characterization of nanofiber mats}

The prepared mats were examined with an optical microscope (Olympus BX51, Japan) to confirm the formation of nanofibers. For further observations, the morphology of nanofibers was investigated by scanning electron microscopy (SEM) (XL 30 ESEM with EDAX, Philips, Netherlands).

The excipients and nanofibers were analyzed over $400-4000 \mathrm{~cm}^{-1}$ wavelength by the Fourier Transform Infrared Spectroscopy (FT-IR, Perkin Elmer Spectrum 100 Spectrometer, USA).

Tensile strength and percentage of elongation at break of mats was determined using TA-XT Plus Texture Analyzer (Stable Micro Systems UK) equipped with $5 \mathrm{~kg}$ load cell. $1 \times 2 \mathrm{~cm}$ mat specimens were mounted on a film holder (A/TG tensile grips) of texture analyzer [13].

The thickness of the nanofiber mat samples was measured using a digital micrometer (Digimatic caliper, Mitutoyo, USA) with a measurement resolution of $1 \mu \mathrm{m}$. Thickness measurement was made from three different points of nanofibers and the mean of measurement and standard deviations were calculated.

Swelling capacity of the nanofiber mat samples was investigated by direct immersion of formulations in PBS ( $\mathrm{pH} 7.4)$ to simulate medium conditions [14]. The swelling degree (S) was calculated according to Eq 1 [15].

$S(\%)=\left\{\left(w_{t}-w_{d}\right) / w_{d}\right\} 100$

where $W_{t}$ is the weight of the swollen sample at time $t$ and $W_{d}$ is the initial weight of the dry sample.

\section{Determination of dexpanthenol}

The high performance liquid chromatography (HPLC) system (Hewlett Packard-1100) consisted of $\mathrm{C} 18$ reverse phase column (ACE 5C18 $250 \mathrm{~mm} \times 4.6 \mathrm{~mm}$ ) with $20 \mu \mathrm{L}$ sample loop was used to determine DEX. The mobile phase was a mixture of 10:90 (v:v) acetonitrile and 0.01 $\mathrm{M}$ ortho-Phosphoric acid. The flow rate, injection volume and UV wavelength were set at $1 \mathrm{~mL} / \mathrm{min}$ at $25^{\circ} \mathrm{C}, 10 \mu \mathrm{L}$ and $206 \mathrm{~nm}$, respectively. The HPLC method was validated via linearity, accuracy and recovery, precision, specificity, limit of detection (LOD) and limit of quantification (LOQ) and stability.

\section{Drug-loading capacity}

The weighed formulation samples were dissolved with PBS ( $\mathrm{pH}$ 7.4). Then, the mixture was shaken at $200 \mathrm{rpm}$ for $24 \mathrm{~h}$. Finally, the drug concentrations were determined by analytical method that mentioned above. Drug loading capacity was calculated by dividing practical DEX concentration with theoretical DEX concentration.

\section{Evaluation of in-vitro release of dexpanthenol}

In-vitro release of DEX through nanofiber mats were performed by dialysis bag diffusion technique. The weighed samples of nanofiber mats were placed in cellulose dialysis bag membranes with molecular weight cut off 12$14,000 \mathrm{D}$, the membranes were put into $7 \mathrm{~mL}$ of PBS ( $\mathrm{pH} \mathrm{7.4).} \mathrm{The} \mathrm{study} \mathrm{was} \mathrm{performed} \mathrm{in} \mathrm{water}$ bath at $37^{\circ} \mathrm{C}$ and the system mixed magnetically at $600 \mathrm{rpm}$. The amount of DEX released was determined by validated HPLC method.

\section{Sterilization and evaluation of sterility}

DEX loaded and unloaded nanofiber mats were sterilized by UV (UVP-CL 1000, Ultraviolet Crosslinker, UK) cabinet at $254 \mathrm{~nm}$ to give a total

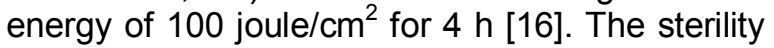
was controlled by microbiological observation.

\section{Cell culture}

Primary human dermal fibroblast-adult (HDFa, Invitrogen C-013-5C) cells were cultured in Medium-106 (Cascade Biologics) supplemented with low serum growth supplement (LSGS, Cascade Biology). Cells were maintained at 37 ${ }^{\circ} \mathrm{C}$ in a humidified atmosphere of $5 \% \mathrm{CO}_{2}$ and $95 \%$ air at $37{ }^{\circ} \mathrm{C}$. Cells obtained from early passages (passages $4-5$ ) to eliminate the alterations in morphology, response to stimuli, growth rates of cells were used for the following experiments.

Coverslips (35 $\mathrm{mm}$ in diameter) were pre-coated with freshly prepared nanofibers, dried by air and were sterilized by UV light for $24 \mathrm{~h}$, placed in a 12-well culture plate. The cells were seeded on the membrane-coated coverslips at a density of $5000 \mathrm{cells} / \mathrm{cm}^{2}$. After 1,3 and 5 days of culture, samples were rinsed twice with phosphatebuffered saline (PBS) to remove the nonadherent cells. Subsequently, membrane-coated coverslips were incubated with 3-(4,5dimethylthiazolyl-2)-2,5-diphenyltetrazolium bromide (Invitrogen; MTT) (5 $\mathrm{mg} / \mathrm{mL}$ ) to determine the cell viability. After $4 \mathrm{~h}$ of incubation at $37^{\circ} \mathrm{C}$, dimethyl sulfoxide was added to 
dissolve the red-colored formazan crystals. The absorbance of the formazan solution was measured in a microplate reader (Varioscan Multimode Flash Reader) at $540 \mathrm{~nm}$. Results were the Mean \pm Standard Error of the Mean (Mean \pm SEM) from at least three different experiments.

\section{Statistical analysis}

Data were analyzed using unpaired t-test and analysis of variance (one-way ANOVA) followed by a Tukey's multiple comparison test (GraphPad Prism, version 6.02 GraphPad Software Inc). Differences were considered significant at $p<$ 0.05).

\section{RESULTS}

\section{Microscopic features of nanofibers}

Small beads were observed in formulations prepared with PLGA in THF/DMF (F1) and $\mathrm{PEO} /$ Chitosan in Acetone/DCM (F7 and F8) Figure 1). The electrospun materials, PLGA in DMF (F3) and PEO/Chitosan in acetic acid solution (F6), could not collect on the collector covered with aluminum foil. Finally; the solutions, PLGA in HFIP, PEO in distilled water and PCL in DCM/DMF were successfully prepared with and without DEX (F2, F4, F5, F9, F10 and F11) and the following studies were performed with these formulations (Figure 2, Figure 3 and Figure 4).

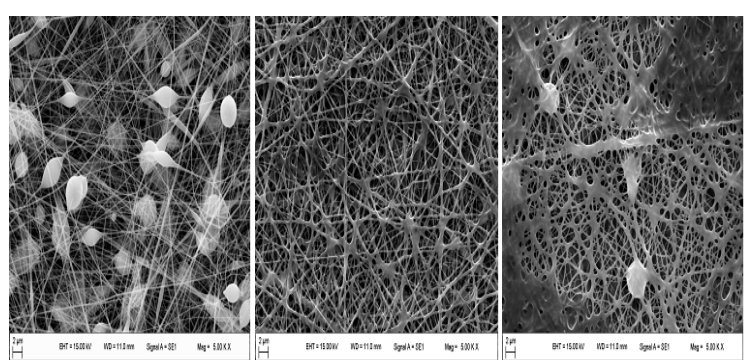

Figure 1: SEM images of $F 1, F 7$ and $F 8$ formulation (PLGA in THF-DMF \% 15, PEO/chitosan (1:1) in acetone/DCM and PEO/chitosan (1.4:0.6) in acetone/DCM)

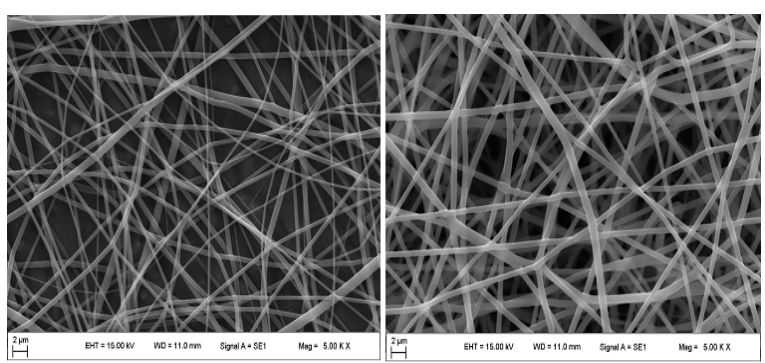

Figure 2: SEM images of $\mathrm{F} 2$ and $\mathrm{F} 4$ formulations (PLGA in HFIP \% 15 and PLGA+DEX in HFIP \% 15)

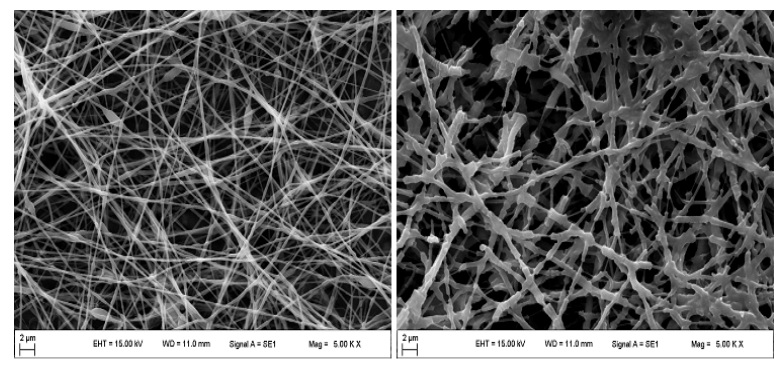

Figure 3: SEM images of F5 and F9 formulations (PEO in distilled water and PEO + DEX in distilled water)
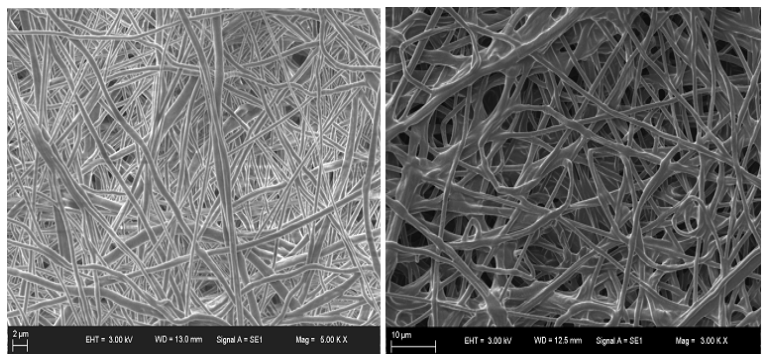

Figure 4: $S E M$ images of $F 10$ and $F 11$ formulation (PCL in DCM/DMF and PCL + DEX in DCM/DMF)

\section{FT-IR spectra of excipients and nanofibers}

The FT-IR analysis of pure excipients and drug loaded and unloaded nanofiber mats were shown in Figure 5. The specific bounds for each component could be seen from the figure.

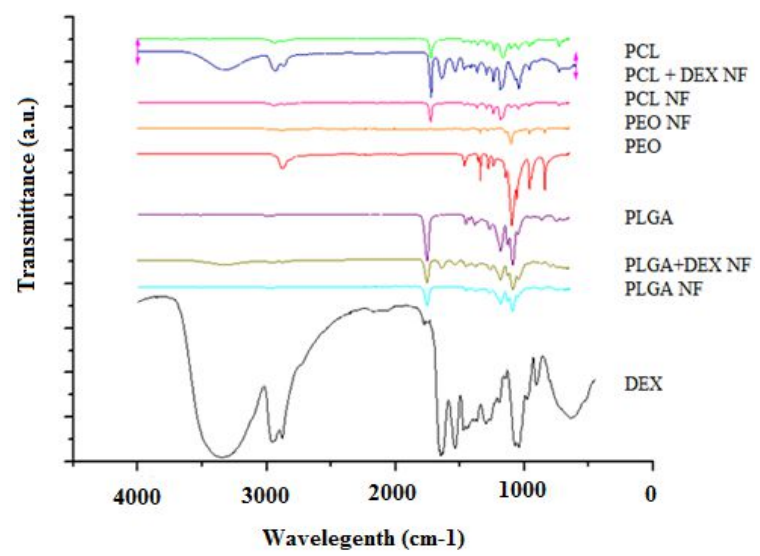

Figure 5: FTIR spectra for DEX loaded and unloaded nanofiber mats and pure substances for the spectral range between 4000 and $400 \mathrm{~cm}^{-1}$ (NF; nanofiber)

\section{Tensile strength and elongation of nanofibers}

The tensile strength and elongation percentage of formulations are shown in Table 3 . The tensile strength and elongation percentage of nanofiber mats decreased with incorporating DEX to formulations. 
Table 3: Tensile strength and elongation of the mats

\begin{tabular}{lcc}
\hline $\begin{array}{l}\text { Formulation } \\
\text { code }\end{array}$ & $\begin{array}{c}\text { Tensile } \\
\text { strength } \\
\left(\mathbf{N} / \mathbf{c m}^{2}\right)\end{array}$ & $\begin{array}{c}\text { Elongation } \\
\mathbf{( \% )}\end{array}$ \\
\hline F2 & $0.657 \pm 0.001$ & $24.545 \pm 0.362$ \\
F4 & $0.0005 \pm 0.0000$ & $12.845 \pm 0.274$ \\
F5 & $0.0028 \pm 0.0001$ & $16.276 \pm 0.184$ \\
F9 & $0.0001 \pm 0.0000$ & $2.639 \pm 0.393$ \\
F10 & $0.817 \pm 0.0001$ & $35.81 \pm 0.952$ \\
F11 & $0.0038 \pm 0.0001$ & $28.285 \pm 0.538$ \\
\hline
\end{tabular}

\section{Thickness of the nanofiber mats}

The highest thickness was observed with PEO and PCL had lowest value (Table 4). DEX loaded formulations had higher thickness than unloaded ones for all formulations.

Table 4: The thickness of nanofiber mats

\begin{tabular}{lcc}
\hline $\begin{array}{l}\text { Formulation } \\
\text { code }\end{array}$ & Polymer/drug & Mean $(\mathbf{m m})$ \\
\hline F2 & PLGA & $0.100 \pm 0.03$ \\
F4 & PLGA+Dex & $0.163 \pm 0.01$ \\
F5 & PEO & $0.127 \pm 0.05$ \\
F9 & PEO+DEX & $0.184 \pm 0.03$ \\
F10 & PCL & $0.053 \pm 0.01$ \\
F11 & PCL+Dex & $0.120 \pm 0.03$ \\
\hline
\end{tabular}

\section{Swelling of nanofiber mats}

The swelling percentages were $34.44 \pm 1.05$, $18.59 \pm 2.11,86.06 \pm 3.25$ and $44.62 \pm 1.75$ for PCL, PCL+DEX, PLGA and PLGA+DEX, respectively. The swelling test could not be performed with PEO and PEO + DEX nanofiber mats (F5 and F9) because, after the formulations were submerged in water, they dissolved, immediately

\section{Analytical method for determination of dexpanthenol}

A new HPLC method was developed to determine DEX concentration in samples. The method was validated via several parameters according $\mathrm{ICH}$ guidance [17]. Coefficient of determination was 0.9986 . The relative standard deviations were less than $2.0 \%$ for accuracy, precision/repeatability which confirmed validation of method. LOD and LOQ were 0.122143 and $0.370131 \mu \mathrm{g} / \mathrm{mL}$, respectively. The stability of DEX solution was examined for $48 \mathrm{~h}$ and the concentration did not change.

\section{Drug-loading capacity}

The drug loaded in the nanofiber mats was determined as mentioned above. The load capacity was $95.42 \pm 3.74,85.4 \pm 0.23$ and 98.42 $\pm 1.93 \%$ for F4, F9 and F11, respectively. The one-way ANOVA test applied to the results gave f-ratio value of 0.19647 , the p-value of 0.831418 . The result was not significant at $p<$ 0.05 .

\section{In-vitro release of dexpanthenol}

In-vitro release studies, such as in the swelling test, could not be performed with the PEO + DEX formulation due to high water solubility of PEO. The PEO + DEX mats dissolved immediately and the drug was released after immersing in PBS. The release percentage for F4 and F11 was $54.24 \pm 1.15$ and $98.66 \pm 1.27$, respectively (Figure 6).

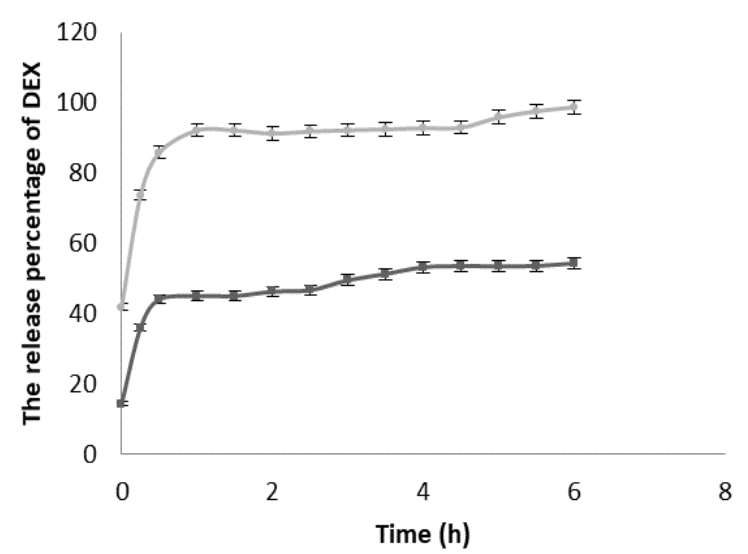

Figure 6: In-vitro release of DEX from the formulations $(\bullet P C L+D E X, \backsim P L G A+D E X)$

\section{Sterility of the mats}

Nanofiber mats were sterilized by UV method before cell culture studies. The microbiologic investigation showed that all formulations were sterile after UV irradiation.

\section{Cell proliferation}

Figure 7 shows the proliferation rate of HDFa cells on different nanofibers after 1,3 and 5 days of in-vitro cell culture. After 1-day culture, it was determined that cell viability on DEX + PCL, DEX + PEO and DEX + PLGA nanofibers coated slides were significantly higher than and unloaded PCL, PEO, PLGA nanofibers coated slides, respectively $(p<0.05)$. However, only DEX + PEO formulation showed lower cell viability than uncoated control slide for the first day. Moreover, at the 3-day of culture, numbers of cells increased to approximately two times higher than 1-day of culture in all slides. Only DEX loaded PLGA fibers significantly improved the cell viability compared to unloaded PLGA fiber coated slides $(p<0.05)$; while there was no significant increase in DEX loaded PCL and PEO fibers compared to unloaded PCL and PEO formulations $(p>0.05)$. At the 5-day of culture, 
DEX loaded PLGA coated fibers significantly enhanced cell proliferation compared to unloaded PLGA coating and control $(p<0.05)$. The graphs show the comparison of HDFa cell viability between Dex-modified and unmodified nanofiber coated cover slides.

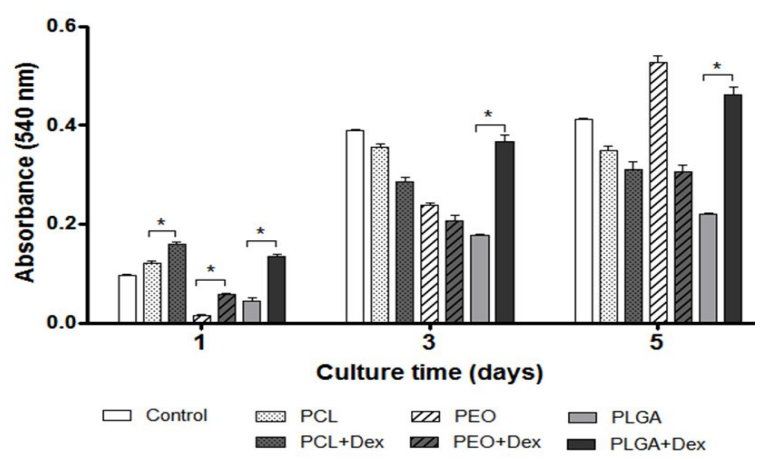

Figure 7: The result of cell viability tests

\section{DISCUSSION}

The macroscopic observation results shown that nanofiber mats could prepare successfully with each polymer. But, the best result was obtained with PLGA. There was no fracture and beads on PLGA figures with and without DEX. The scaffold like structure of PLGA mats could provide a suitable space for cell growth.

Infrared spectroscopy has been frequently used to investigate the conformational changes of nanofiber mats. The main characteristic vibration bands of DEX functional groups were observed in the FT-IR spectra [18]. As it was seen in FTIR spectra, in bulk PLGA polymer, PLGA electrospun nanofibers and PLGA + DEX nanofibers, the $\mathrm{C}=\mathrm{O}$ stretch and the $\mathrm{C}-\mathrm{O}$ stretch hovered around 1750 and $1050 \mathrm{~cm}^{-1}$ respectively and bands around $3,000 \mathrm{~cm}^{-1}$ were observed due to the alkyl groups. There was no change in FT-IR spectra of bulk PLGA and PLGA nanofibers.

Regarding the PCL spectrum, strong bands such as the carbonyl stretching mode around 1723 $\mathrm{cm}^{-1}$ could be easily identified for pure PCL, PCL nanofiber and $P C L+D E X$ nanofibers mats. The band around $1290 \mathrm{~cm}^{-1}$ which was seen in all spectra was assigned to the backbone $\mathrm{C}-\mathrm{C}$ and $\mathrm{C}-\mathrm{O}$ stretching modes in the crystalline PCL.

The FT-IR were used to determine molecular interactions within PEO and DEX loaded PEO nanofibers The figure showed that there is no significant interactions between drug loaded and unloaded nanofibers. A band around $2900 \mathrm{~cm}^{-1}$ was seen in the FT-IR spectra of PEO nanofibers and pure PEO that is attributed to the symmetric and asymmetric $\mathrm{C}-\mathrm{H}$ stretching modes. And also the bands at about 1456-1350 $\mathrm{cm}^{-1}$ and 1102-962 $\mathrm{cm}^{-1}$ were specific for $\mathrm{CH}_{2}-$ group and $\mathrm{C}-\mathrm{O}$ group, respectively.

The spectra of all DEX-loaded nanofibers had bounds around $3,800 \mathrm{~cm}^{-1}$ that specific for DEX substance. In addition, there was no peak revealed to solvents used for fiber spinning that means there were no residual solvents left after spinning. The absence of residual solvents is an important factor in application of nanofiber mats for wound healing since it may be harmful in biomedical applications.

The presence of DEX weakened the cohesive force between chain molecules of polymer and therefore, the tensile strength of mats reduced. As it was shown with SEM images PEO nanofiber mats with DEX (F9) have some broken areas that indicate lower tensile strength of this formulation. The lowest values were obtained with F9 formulations for tensile strength. Formulations with PEO are more breakable than others. PLGA is a very brittle material, which can easily break if the stress increases while PCL is a flexible polymer [19]. The SEM images also confirmed this data.

The thickness of fiber could vary depending on polymer type, active agents, collection time, etc. The collection time was not changed in this study. But, thickness changed depending on polymer type and the presence of active substance. As mentioned above, presence of DEX increased the thickness due to filling effect of active substance.

The change in weight of the specimens gives an idea of how much water they can hold and swell. The presence of DEX was decrease swelling capacity due to gaps filling effect of active substances. Other formulations showed high swelling capacity due to porous structure of nanofiber mats. High swelling capacity is an important feature in terms of fluid absorption, especially in exudative tissues.

High drug loading was expected due to the passive drug loading technique. The drug incorporated into the polymeric solution and after spinning the solidified drug was entrapped in the fiber mats. Therefore, the risk of drug loss is very low during process. The drug loading was high for all formulations and the differences were not significant.

$A$ rapid release was observed with the $F 11$ formulation while a controlled release was 
obtained with the F4 formulation after six hours. Since healing process takes a long time, the goal was to achieve a controlled release of the active and also for the nanofibers not to dissolve easily at the area of application. They should provide a scaffold for growing cells and then the nanofiber mats have to degrade by the time to allow drug release. From this point of view, PLGA + DEX formulation has more advantage than $\mathrm{PCL}+$ DEX and PEO + DEX formulations.

The UV radiation is used for disinfection purposes and this sterilization method has advantages such as no need for heating and chemicals [20]. In our study the nanofiber mats sterilized by UV method before cell culture studies.

Recent studies have shown that the properties of a scaffold are very important in regulating the biological properties of cells and in the formation of tissue substitutes (buraya kendi iyi literatürlerinden birini eklyecebilirsin). HDFa cells are frequently used in the in vitro studies on tissue scaffold studies [21,22]. These cells capable to synthesize and secrete extracellular matrix proteins and collagen under cell culture conditions. In this study, it was demonstrated that the HDFa cells could adhere and proliferate on all the tested nanofibers which are an essentials property for scaffold applications. Furthermore, it was determined that only DEX loaded PLGA coated fibers significantly induced HDFa cell proliferation compared to unloaded PLGA coating and control at the end of the fifth day. Our results suggest that DEX loaded PLGA may use as an effective alternative biocompatible formulation for the scaffold fiber engineering.

\section{CONCLUSION}

DEX-loaded PLGA, PCL and PEO nanofibers have been suitably prepared by electrospinning method. Rapid drug release was obtained from PEO mats while PLGA and PEO mats had controlled release. Slower release is an advantage for long wound healing process. PLGA+DEX formulations significantly induced cell proliferation. Furthermore, PLGA + DEX nanofiber formulation is a promising alternative for treatment of skin lesions.

\section{DECLARATIONS}

\section{Acknowledgement}

The authors acknowledge the access granted for the use of UPCL and FTIR facilities by Ege University, Faculty of Pharmacy, Pharmaceutical Sciences Research Centre (FABAL) were used.
The authors would like to thank to center, as well as Cenk Celik for help with electrospinning device.

\section{Disclosure of interest}

No conflict of interest is associated with this work.

\section{Contribution of authors}

We declare that this work was done by the authors named in this article and all liabilities pertaining to claims relating to the content of this article will be borne by the authors. Firs author is corresponding author and she wrote the manuscript. And also she worked on preparation of formulations, characterization of formulations. Second author is worked on all methods part except cell culture studies. Third author is developed HPLC method and prepared PEO nanofiber mats. Fourth author performed cell culture studies. And last one is consultant of study.

\section{REFERENCES}

1. Dwivedi $C$, Pandey $H$, Pandey AC, Ramteke PW. Nanofibre Based Smart Pharmaceutical Scaffolds for Wound Repair and Regenerations. Curr. Pharm. Des. 2016; 22(11): 1460-1471.

2. Eroğlu I, Gökçe EH, Tsapis N, Tanrıverdi ST, Gökçe G, Fattal E, Özer Ö. Evaluation of characteristics and in vitro antioxidant properties of RSV loaded hyaluronic acid-DPPC microparticles as a wound healing system. Colloids Surf B Biointerfaces. 2015; 1(126): 50-57.

3. Shin SH, Purevdorj O, Castano O, Planell JA, Kim HW. A short review: Recent advances in electrospinning for bone tissue regeneration. J. Tissue Eng. 2012; 3: 1-10.

4. Es-saheb M, Sherif E-SM, El-Zatahry A, El Rayes MM, Khalil K.A. Corrosion Passivation in Aerated $3.5 \% \mathrm{NaCl}$ Solutions of Brass by Nanofiber Coatings of Polyvinyl Chloride and Polystyrene. Int. J. Electrochem. Sci. 2012; 7(11): 10442 - 10455.

5. Bazilevsky A.V, Yarin AL, Megaridis CM. Coelectrospinning of core-shell fibers using a single-nozzle technique. Langmuir 2007; 23(5): 2311-2314.

6. Abdelrazek Khalil K, Almajid AA, El-Danaf EA, El Rayes MM, Sherif E-SM. Direct Fabrication of Yttrium Aluminium Garnet Nanofibers by Electrospinning. Int. J. Electrochem. Sci. 2012; 7: 12218-12226.

7. Agrawal CM, Ray RB. Biodegradable polymeric scaffolds for musculoskeletal tissue engineering. J Biomed Mater Res. 2001; 55(2): 141-150.

8. Steven T, Boyce ST. Design principles for composition and performance of cultured skin substitutes. Burns. 2001; 27: 523-533. 
9. Luong-Van E, Grondahl L, Chua KN, Leong KW, Nurcombe V, Cool SM. Controlled release of heparin from poly(epsilon-caprolactone) electrospun fibers. Biomaterials, 2006; 27(9):2042-2050.

10. Stozkowska W, Piekos R. Investigation of some topical formulations containing dexpanthenol. Acta Pol Pharm, 2004; 61(6): 433-437.

11. Hanck AB, Goffin H. Dexpanthenol (Ro 01-4709) in the treatment of constipation. Acta Vitaminol Enzymol. 1982; 4(1-2): 87-97.

12. Dash TK, Konkimalla VB. Poly-€-caprolactone based formulations for drug delivery and tissue engineering: $A$ review. J. Control. Release, 2012; 158(1): 15-33.

13. Tanrıverdi ST, Hilmioğlu Polat S, Yeşim Metin D, Kandiloğlu G, Özer Ö. Terbinafine hydrochloride loaded liposome film formulation for treatment of onychomycosis: in vitro and in vivo evaluation. $J$ Liposome Res. 2016; 26(2): 163-173.

14. Sah M, Pramanik K. Soluble-eggshell-membrane-proteinmodified porous silk fibroin scaffolds with enhanced cell adhesion and proliferation properties. Inc. J. Appl. Polym. Sci.2014; 131(8): 40138.

15. Qi QL, Li Q, Lu J, Guo ZX, Yu J. Preparation and Characterization of Soluble Eggshell Membrane Protein/Chitosan Blend Films. Chinese J. Polym. Sci. 2009; 27(3): 387-392.
16. Bellincampi $L D$, Dunn MG. Effect of crosslinking method on collagen fiber-fibroblast interactions. J App Polymer, 1997; 63(11): 1493-1498.

17. Commission of the European Communities. Validation of analytical procedures. Proceedings of International Conference on Harmonisation (ICH) (1996).

18. Mills T, Roberson J. Instrumental Data for Drug Analysis. 2005, CRC press.

19. Kim JY, Cho DW. Blended PCL/PLGA scaffold fabrication using multi-head deposition system. Microelectron Eng. 2009; 86: 1447-1450.

20. Dai Z, Ronholm J, Tian Y, Sethi B, Cao X. Sterilization techniques for biodegradable scaffolds in tissue engineering applications. J. Tissue Eng, 2016; 7: 1-13.

21. Jia J, Duan YY, Yu J, Lu JW. Preparation and immobilization of soluble eggshell membrane protein on the electrospun nanofibers to enhance cell adhesion and growth. J Biomed Mater Res A. 2008; 86(2): 364373.

22. Busra FMh, Lokanathan $Y$, Nadzir MM, Saim A, Idrus $R B H$, Chowdhury SR. Attachment, Proliferation, and Morphological Properties of Human Dermal Fibroblasts on Ovine Tendon Collagen Scaffolds: A Comparative Study. Malays J Med Sci. 2017; 24(2): 33-43. 